\title{
Provocaciones sobre el tema "Extractivismo y Desarrollo"
}

\author{
Héctor Alimonda ${ }^{1}$ \\ Universidad Federal Rural de Rio de Janeiro, Rio de Janeiro, Brasil. \\ Email: hectoralimonda@gmail.com
}

Resumen: Este trabajo se cuestiona la capacidad de los modelos exportadores de bienes naturales primarios para promover el desarrollo en nuestro continente, revisando el largo debate teórico que el pensamiento crítico ha realizado al respecto, y planteando la necesidad de superar el modelo extractivista, desconstruyendo las ideas establecidas respecto a sus beneficios. rrollo.

Palabras clave: extractivismo, metabolismo sociedad/naturaleza, desa-

\section{Provocationson the subject "Extractivism and Development"}

\begin{abstract}
This paper questions the capacity of exporting models of primary natural resources to promote development in our continent, reviewing the long theoretical debate that critical thinking has made in this regard, and considering the need to over come the extractive model, deconstructing the established ideas about its benefits.
\end{abstract}

Keywords: extractivism, metabolism society/nature, development.

\section{Provocaçõessobreo tema "Extrativismo e Desenvolvimento"}

Resumo: Neste artigo se questiona a capacidadedos modelos de exportaçao dos recursos naturaisprimáriospara promover o desenvolvimentoemnosso continente, revendo o longo debateteóricoque o pensamento críticofeza este respeito,e tendo em contaa necessidade de superaro modeloextrativista, desconstruindo as idéiasestabelecidassobre seusbenefícios.

Palavras-chave: extrativismo, metabolismosociedade/natureza, desenvolvimento.

El estímulo del amigo Antonio Elizalde me recordó inmediatamente a Boaventura de Souza Santos diciendo que los sociólogos son muy buenos para prever el pasado. Y claro que, como una marca generacional, repetida en cada uno de nuestros países, su incitación a formular preguntas me evoca aquel comienzo insuperable del Vargas Llosa de 1969, cuando Santiago, el protagonista de “Conversación en la Catedral”, observa la avenida 
Tacna desde la puerta de La Crónica (automóviles, edificios descoloridos, esqueletos de carteles emergiendo de la neblina) y se hace la persistente y compartida pregunta: “¿cuándo se jodió el Perú?”.

Simplificando el repertorio, y yendo a un tema absolutamente contemporáneo (y del futuro próximo), quiero retomar una pregunta clásica en el pensamiento latinoamericano: Cuál es la capacidad de los modelos exportadores de bienes naturales primarios para promover un desarrollo cualitativamente valioso?

Este texto no pretende ninguna originalidad. Apenas tiene el objetivo de recordar que el debate actual sobre los modelos extractivistas y su virtuosidad para promover el desarrollo tiene antecedentes ilustres en el pensamiento social desde el siglo XIX, y en especial en la tradición de la cultura política latinoamericana. Y eso supone, precisamente, una desconstrucción o desnaturalización de algunas ideas preestablecidas. ${ }^{2}$

\section{Primera escena: Entre el Palacio de Invierno de San Petesburgo y el Carondelet de Quito, con la participación estelar de Carlos Marx, Nikolái Danielson y Rafael Correa}

Nuestra primera provocación se origina en afirmaciones de un gran provocador performático, el presidente de la República del Ecuador, Rafael Correa. En reiteradas ocasiones, Correa ha atacado a la que denomina pseudoizquierda conservadora por su oposición al modelo extractivista de la gran minería serrana y de la explotación de hidrocarburos en la región amazónica. Y volvió a hacerlo después de su último triunfo electoral, en entrevista al diario argentino Página 12 (publicada en la edición del 21 de febrero de 2013). En esa ocasión, el presidente y economista Correa lamentó haberse perdido una clase de marxismo leninismo (sic - lo menos que puede decirse es que se trata de una expresión fuera de uso) donde se habría presentado la idea de que no debían explotarse los recursos naturales, contradiciendo la lógica del mejoramiento social a partir del desarrollo de las fuerzas productivas $^{3}$. Hasta donde conocemos la polémica, Rafael Correa recibió respuestas atinadas de Eduardo Gudynas (2013) y de Joan Martínez Alier (2013), que se refirieron a la crítica a los procesos de producción, a la noción de acumulación originaria, reconstruida por David Harvey como acumulación por desposesión, y (lo que nos parece más incisivo) al concepto de metabolismosociedad/naturaleza. ${ }^{4}$

Pero queremos traer aquí otro elemento crítico, muy poco reconocido cuando de marxismo se trata (y que, evidentemente, el presidente Correa puede muy bien no conocer, sin que eso signifique ningún menoscabo para él, ¡hombre, que ya tiene mucho de qué ocuparse!). Se trata de las dudas que, hacia el final de la vida de Marx, aparecen en su correspondencia con el traductor de “El Capital” al ruso, Nikolái Danielson, sobre el carácter necesariamente progresivo, desde el punto de vista socio-político, que ten- 
dría el desarrollo de las fuerzas productivas. Estas observaciones, limitadas a un intercambio epistolar de alto nivel teórico, resultan de una importancia fundamental, ya que alteran toda la lectura sedimentada de la obra de Marx y las imputaciones de un automatismo economicista en la explicación de los procesos sociales vinculados justamente con la relación entre el capitalismo y el desarrollo (que existió realmente, pero que, al parecer, Marx fue dejando de lado).

El 5 de febrero de 1879, Danielson ha escrito una larga carta a Marx, exponiéndole su amargo escepticismo sobre las virtudes del desarrollo derivado de la expansión de líneas ferroviarias por el interior de Rusia, que estaban provocando desintegración social y destrucción ambiental. Y es importantísimo consignar la respuesta de Marx, especialmente recordando sus famosos artículos de 1853 que elogiaban la construcción de ferrocarriles en la India, los cuáles (creía en la época) provocarían casi automáticamente la transformación modernizadora de la sociedad hindú, o sus ilusiones de que los intensos flujos de libre comercio interoceánico irían a transformar a Panamá en una potencia internacional. No solamente Marx no se escandalizó por el análisis de Danielson, sino que además adelantó una reflexión estratégica que permite verificar su percepción de una diferenciación en el espacio del desarrollo capitalista, que no solamente abandona la referencia al modelo euro-céntrico como paradigma fatal, como avanza hacia una tipología posible de capitalismos periféricos, sujetos a una diferente lógica de articulación y de funcionamiento, y donde los efectos de la incorporación a la dinámica internacional de acumulación serían altamente diferenciados de los modelos centrales.

Responde Marx a Danielson, el 10 de abril de 1879:

"Por otra parte, la aparición del sistema ferroviario en los principales países capitalistas permitió (e incluso obligó) que naciones en las cuales el capitalismo abarcaba sólo a una reducida capa superior de la sociedad, crearan y ampliaran repentinamente su infraestructura capitalista en una medida enteramente desproporcionada al conjunto del organismo social. Por eso no cabe la menor duda de que en esos estados el ferrocarril ha acelerado la desintegración social y política, de la misma manera que en los estados más desarrollados ha acelerado la transformación de la producción capitalista”. Y más adelante vuelve con una referencia al libre comercio y la globalización: "En general, los ferrocarriles dieron un inmenso impulso al desarrollo del comercio exterior, pero en los países que exportan principalmente materias primas, el comercio aumentó la miseria de las masas (...) porque desde el momento en que toda producción local pudo convertirse en oro internacional, muchos artículos anteriormente baratos (...) encarecieron y desaparecieron del consumo popular, en tanto que la producción misma se transformó de acuerdo a su adaptabilidad a la exportación”(en Aricó, 1981, pág. 127).

Nos parece que este breve texto tiene una importancia capital. Se 
hace evidente que el pensamiento de Marx mucho ha madurado desde sus escritos de la década de 1850. Ya no piensa en una determinación lineal del "progreso histórico" a partir de la activación de fuerzas productivas cada vez más desarrolladas. En las condiciones coloniales (como la India) o periféricas (como América Latina) ese "desarrollo de fuerzas productivas" puede implicar nada más que trasplantes tecnológicos de enclave, aislados, ingobernables por las instancias nacionales e inasimilables para las sociedades locales: en esos casos, se trata de una desproporción de escalas, que bloquea la transferencia de cualquier estímulo y que acostumbra tener resultados catastróficos. La consecuencia, entonces, no es el "progreso", sino "la desintegración social y política”, es decir, la postración o destrucción de las comunidades locales y el incremento de la heterogeneidad estructural y de la dependencia de las sociedades nacionales. Y esta consideración puede aplicarse, de forma puntual, a la experiencia del macroextractivismo agrícola y minero que se extiende actualmente por la región latinoamericana ${ }^{5}$.

De la misma forma, la introducción del comercio internacional y la consiguiente reorganización de los sistemas productivos de las colonias y de los países productores de materias primas (incluyendo sus agroecosistemas) llevan a la miseria a las masas populares. Creemos que a partir de este párrafo es posible intuir que Marx, en sus últimos años de vida, estaba reelaborando toda su concepción de causalidad y progreso histórico. La lógica del desarrollo capitalista y sus consecuencias aparecen diferenciadas según la posición de cada sociedad en una división internacional del trabajo y de la producción, resaltando el carácter destructivo de las fuerzas productivas capitalistas avanzadas actuando en el seno de las sociedades periféricas. En ese contexto, también, en un diálogo marcado por las preocupaciones ambientales de Danielson, no parece desatinado suponer que esa reformulación de su pensamiento implicaba ahora, lógicamente, una diferente valoración de la problemática de la relación entre desarrollo histórico y naturaleza.

Luego de la muerte de Marx, Danielson continuó su correspondencia con Federico Engels, con quién tenía amargas divergencias, justamente porque Engels defendía férreamente la perspectiva del carácter necesariamente progresivo en términos sociales y políticos del desarrollo de las fuerzas productivas. Finalmente, el 3 de noviembre de 1893, en la que quizás sea su carta más dramática, Danielson introdujo la idea de un desarrollo capitalista que destruye no solamente sus propias condiciones de reproducción (a la manera de lo que James O`Connor ha denominado "la segunda contradicción del capitalismo"), sino que depreda inclusive a las propias relaciones sociales básicas constituyentes de la sociedad, al estilo del capitalismo neoliberal latinoamericano, aplicado sobre relaciones sociales y políticas mucho menos consolidadas que las del capitalismo central. En esas condiciones, Danielson no entiende por qué debería cumplirse la norma (¿metafísica?) de que el resultado sería una maduración de condiciones y de sujetos históricamente más progresivos. 
“En mi opinión, el aspecto positivo del modo de producción capitalista no contrarresta su aspecto negativo: el lado progresista tiene repercusiones en una porción muy reducida de la población, mientras que el lado negativo abarca a la mayor parte. La evolución de este modo de producción detiene su propio desarrollo; esto significa que debemos buscar otra salida; será inútil esperar formas más altas de desarrollo como consecuencia ineluctable del modo de producción capitalista y del antagonismo social creado por él.

\begin{abstract}
¿Acaso la hambruna de 1891 no dejó huellas? ${ }^{6}$ Lo que ocurrió en el año de hambruna representa la forma atenuada de lo que podemos esperar para el futuro. No tuvo ninguna fuerza de creación. ¿Qué nos enseñó dicho año? ¿Qué hay que hacer para librarse de la repetición de esa calamidad? Se nos dice que tal calamidad no sólo es inevitable, sino que en el futuro cobrará un aspecto más agudo; no hay salida, y en un futuro cercano se esperan enormes sufrimientos y el despilfarro de vidas humanas, y finalmente, cuando a partir de este modo de producción (que es la causa directa de tales sufrimientos) estalle el antagonismo social que él genera, podremos esperar el desarrollo de una forma más elevada. ¿Y si el modo de producción capitalista no genera un antagonismo dualista como el que se produjo en Europa Occidental? ¿ ¿Y si el desarrollo de este modo crea los obstáculos para su propio desarrollo?
\end{abstract}

Los resultados del desarrollo en un país de alta cultura y en un país de cultura rudimentaria son totalmente diferentes. En el primer caso, este desarrollo lleva a la formación de una fuerza organizada, consciente de su influencia; en el otro, en cambio, desbarajusta al conjunto de la organización productiva social; lleva al inmenso despilfarro de vidas humanas y de fuerzas productivas, ya que proporciona trabajo a una parte cada vez menor de la población, al mismo tiempo en que disminuye el nivel económico de toda la población (...) El capitalismo crea obstáculos tan grandes para su propio desarrollo que el paso a una forma más elevada resulta imposible” (en Aricó, 1981, págs. 313/314).

Danielson completa aquí, con un sentido político, la perspectiva vislumbrada por Marx en su carta del 10 de abril de 1879, que citamos más arriba. Las violentas recomposiciones de las relaciones sociedad/naturaleza implicadas por la mercantilización de la tierra y del trabajo, por la implantación de agriculturas de exportación o por el aterrizaje de los macro-enclaves de tecnología avanzada no tienen por qué tener como resultado necesario la formación de nuevos sujetos políticos y sociales y un impulso hacia el desarrollo y la modernización, como supusieron Engels y la Segunda Internacional (e anche la Tercera). La capacidad destructiva del capitalismo se ejerce con una potencia que bloquea la posibilidad misma del desarrollo, sumiendo a los países de la periferia en un desbarajuste del conjunto de su organización productiva y social. Encontramos aquí correspondencia con 
la visión del "desarrollo del subdesarrollo", de André Gunder Frank, y también con los análisis que, desde la década de 1960, viene aportando el profesor Aníbal Quijano sobre la producción y reproducción de la heterogeneidad estructural en América Latina. Las palabras de Danielson parecerían estar referidas a la realidad de cada país latinoamericano, luego de décadas sucesivas de ajustes y reformas neoliberales, que aumentaron implacablemente las carencias sociales y los colapsos de los sistemas productivos, en nombre de un futuro nivel de prosperidad que nunca llegó en los marcos del neoliberalismo.

Así como la religión de mercado del neoliberalismo se demostró una falacia, sería bueno que los llamados gobiernos post-neoliberales de la región no reprodujeran la creencia casi religiosa en el fetiche del carácter progresivo automático del desarrollo de las fuerzas productivas, especialmente fútil cuando se fundamenta en la dinámica de los enclaves extractivistas agro-mineros y en precios internacionales altamente variables.

\section{Segunda escena: Recorriendo las periferias, de Lublin, Polonia rusa, a la calle Washington izquierda, Lima}

Intentaré avanzar un poco más. Si lo anterior es aceptado como premisa teórica, deberíamos descartar la lógica de un progreso histórico automático, basado en el desarrollo de las fuerzas productivas. Pero, eliminado ese finalismo, otros elementos analíticos se hacen presentes, y una lectura contemporánea no puede dejar de recordarlos.

No sólo el desarrollo de las fuerzas productivas pierde sus virtuosidades teóricas y prácticas, como se hace evidente la necesidad de incorporar en el análisis a las dimensiones políticas y culturales (claro está que la clasificación epistolar de Danielson entre "altas culturas" y "culturas rudimentarias", propia de la época, resulta hoy absolutamente inadecuada). Nos referimos a la densidad particular de relaciones sociales, en una pluralidad de espacios territoriales construidos a lo largo de temporalidades específicas, que establecen lazos políticos de dominación, resistencia y negociación a nivel local y nacional. En sociedades hasta entonces relativamente marginales a los flujos principales de acumulación global, son este conjunto disputado de relaciones sociales las que constituyen las representaciones sobre la relación sociedad/naturaleza y las que consolidan, por lo tanto, las líneas dominantes de las actividades económicas tradicionales. La inclusión de estas áreas en la lógica global de acumulación implicará una ofensiva político-cultural, impulsada por un modelo de modernidad transnacional, de matriz individualista, euro-céntrica, extractivista. Bajo los efectos de esa ofensiva, las relaciones sociales preexistentes, las configuraciones políticas, culturales y territoriales, las naturalezas, serán recompuestas (o inclusive extintas) según la nueva hegemonía. 
Fue Rosa Luxemburgo (1967) [1912] quién verificó la necesidad de incorporar teóricamente a la dimensión colonial en el sistema teórico marxista, más allá de las referencias marxianas a su importancia para la acumulación originaria. En la culminación de la competencia imperialista por el reparto del mundo periférico y la consecuente carrera armamentista, la gran economista polaca, con sensibilidad y erudición, introdujo a la experiencia colonial en el interior de la teoría económica, destacando su carácter permanente en el capitalismo, y su configuración como subordinación sistemática de sociedades periféricas a la lógica global de acumulación. Estudió la ofensiva europea sobre la China imperial, y ejemplificó con el dominio inglés en la India y en Sudáfrica y con el francés en Argelia la recomposición de formas tradicionales de propiedad o de relaciones familiares para implantar la propiedad privada y adecuarlas al sistema colonial. Y consideró también la subordinación al capital de comunidades, territorios y naturalezas en el interior del capitalismo central, con el ejemplo de la crisis de la pequeña propiedad en el centro y oeste de los Estados Unidos. ${ }^{7}$

Para Rosa Luxemburgo, la acumulación capitalista trabaja con dos lógicas, una donde imperan las imágenes de la normatividad contractual, la paz, la seguridad de la propiedad y la igualdad jurídica (la modernidad) y otra donde se impone como método la violencia, la opresión, la rapiña (la colonialidad). ${ }^{8}$ Lo que queremos destacar es que su perspectiva superó puntos ciegos fundamentales dentro de la tradición marxista, y, al hacerlo, estableció la posibilidad de un diálogo más efectivo con el horizonte problemático contemporáneo.

Recordemos que en 1928, en sus reflexiones del exilio, León Trotsky transitó nuevamente esta problemática, en el primer capítulo de su "Historia de la revolución rusa”. Existirían sociedades (occidentales) donde el desarrollo capitalista avanza "en profundidad", homogeneizando al conjunto de relaciones sociales en una dinámica de modernización. Otras, en cambio, como Rusia, serían el escenario de un desarrollo “en extensión”, que recompone antiguas relaciones sociales y las combina en equilibrios precarios y desiguales.

Una visión que complementaba desde la política a la de Rosa, elaborada desde un capitalismo periférico donde núcleos de acumulación coexistían con la supervivencia cristalizada de antiguos "bloques sociales”, fue la de Antonio Gramsci. Desde su punto de vista, existirían territorios "vacíos para el capital", como los Estados Unidos, donde la hegemonía se basaba en la industria, y donde el fordismo podía organizar al conjunto de la sociedad según su dinámica, mientras en otros países el capital se veía obligado a recomponer permanentemente sus relaciones con "los pensionistas de la historia económica”, lo que daba origen a un estilo contradictorio y desigual de desarrollo.

José Carlos Mariátegui, asentado en un problemático capitalismo dependiente, expresó su descreencia en la capacidad del desarrollo inducido por la vinculación con el mercado internacional a través de enclaves de 
exportación para transformar su sociedad en dirección a la modernidad. Lo que observó fue, en todo caso, la recomposición de un bloque dominante tradicional/moderno, un hibridismo cultural estéril y la reproducción ampliada de la heterogeneidad estructural y del subdesarrollo. Prefirió apostar, entonces, en una propuesta de modernidad alternativa, capaz de integrar en una alianza política al conjunto de sectores sociales en oposición al bloque oligárquico/imperialista, y donde la sobrevivencia de tradiciones comunitarias indígenas era un predicado esencial en una perspectiva post capitalista (y hoy diríamos, además, post desarrollo). En términos políticos concretos, los medios de prensa fundados por Mariátegui denunciaron repetidamente al enclave minero de la Cerro de Pasco Copper Corporation, tanto por la inseguridad fatal a que estaban sometidos sus trabajadores (que provocó la catástrofe de Morococha, en diciembre de 1928) como por la contaminación ambiental provocada por las chimeneas de refinación de la mina ("los humos de La Oroya").

Retrospectivamente, provoca cierta melancolía pensar en los diferentes caminos que podría haber tomado la historia latinoamericana si nuestras izquierdas del siglo XX, en lugar de repetir fórmulas euro-céntricas y deslumbrarse colonizadamente con las luces del centro, hubieran estado afincadas con sus propios pies en tierra americana, ojos, oídos y cabezas abiertas a nuestra realidad, problematizando la noción del carácter necesario y fatal del desarrollo de las fuerzas productivas y comprendiendo que las luchas indígenas y campesinas por defender sus culturas y sus territorios apuntaban precisamente al gran conflicto central que nuestra región vendría a afrontar en el siglo XXI.

En resumen, repensar la relación extractivismo/desarrollo supone trascender los modelos "planos", e incorporar en el análisis al conjunto de dimensiones densas que constituyen las sociedades locales y sus naturalezas, sobre las cuáles el desarrollo capitalista impondrá sus mecanismos destructivos de subordinación/recomposición. Se trata entonces de proceder a operaciones de "internalización de externalidades", que tengan en cuenta no solamente las promesas constructivas de los modelos de desarrollo, sino también sus efectos destructivos sobre sociedades y naturalezas, que crean inmensos e irremediables pasivos culturales y ambientales. Y también, ahora sí, se trata de acompañar las resistencias populares cada vez más plurales y organizadas que se enfrentan a los modelos neo-desarrollistas y macro-extractivistas, en nombre de perspectivas descoloniales y por una modernidad otra.

\section{Tercera escena: de la Avenida Providencia, Santiago de Chile, al "consenso de las commodities" 10}

Prefiero presentar esta última provocación de forma muy escueta. Una vasta tradición político-cultural latinoamericana, desde el siglo XIX, elaboró críticas más o menos difusas, pero efectivas, a la integración subor- 
dinada de nuestros países en el mercado global, como abastecedores de materias primas.

Después de la Segunda Guerra Mundial, cuando el discurso internacional del desarrollo se expandió por nuestra región, ya encontró una tradición latinoamericana que impugnaba los vicios del modelo agro-minero exportador, no solamente por sus consecuencias económicas (la fragilidad de su dependencia de mercados globales, su escasa capacidad multiplicadora para convertirse en motor de crecimiento del conjunto de la economía, o, aunque sea, a nivel local), sino inclusive, más centralmente, por sus efectos en las dimensiones políticas (la oligarquización y el bloqueo de las expresiones populares), sociales (la reproducción de la heterogeneidad estructural y de las desigualdades) y culturales (la persistencia de la colonialidad, la miopía en relación a la propia realidad).

Profundizando esa tendencia, tuvimos durante la década de 1960 referencias intelectuales como el pensamiento de la CEPAL, la obra de los jóvenes Fernando Henrique Cardoso y Enzo Faletto, la interpretación del desarrollo del subdesarrollo de André Gunder Frank, análisis estructurales de la dependencia como los de Celso Furtado ${ }^{11}$ y Ruy Mauro Marini, unos años más tarde la crítica a las economías rentistas... En todas estas perspectivas, que renovaron la imaginación política latinoamericana, era punto común la impugnación del modelo de enclave exportador agro-minero.

Pues bien, es cierto que el mundo cambió (pero no tanto), es cierto que todos estamos más viejos (pero hay nuevos jóvenes). Pero también es cierto que la agenda de las principales protestas sociales organizadas, en toda la región, se va definiendo justamente en contra de los grandes proyectos extractivistas. Y esas resistencias ya han tenido demasiadas criminalizaciones y demasiados mártires.

Como intelectuales, tenemos la responsabilidad de dar continuidad a la tradición del pensamiento crítico latinoamericano, que nos distingue en el tiempo del mundo. Eso supone recoger las voces de nuestros pueblos, oír las voces de la calle, pero también las de los campos y de los bosques, y a partir de allí construir nuestras agendas de investigación. ¿El modelo extractivista es la única forma viable de inserción en el mercado internacional? ¿Los proyectos de mega-obras públicas serán prioritarios para satisfacer las necesidades urgentes de nuestros pueblos, postergadas durante tanto tiempo? ¿Cómo implementar versiones más amigables y propias de modernidad, basadas en principios de "Buen Vivir" y de descolonialidad? Ya que los efectos positivos del extractivismo sobre las sociedades locales, los mercados de trabajo y/o la naturaleza son nulos, ¿¿será por lo menos cierto que esas actividades constituyen fuente indispensable para que nuestros Estados puedan financiar políticas sociales? ¿Lo están efectivamente haciendo ${ }^{12}$ ¿Y cuál es el costo para el sector público de la implantación y funcionamiento de las economías extractivas, a través de renuncia fiscal, subsidios y beneficios impositivos varios, exención de impuestos a las exportaciones y a las ganancias, reintegros por exportaciones, etc., etc.? ¿Y 
el costo de los "pasivos ambientales", que en el caso del extractivismo minero persistirán durante centenas de años?

Debemos preguntarnos por el modelo de sociedad que está siendo construida en nuestros países, que resguarda y amplifica poderes constituidos, y donde la inclusión se limita al consumo. Y recuerdo entonces el grito del general guerrillero José Dolores, conducido a la horca, a William Walker/Marlon Brando en el final de "Queimada”: “inglés, es mejor saber hacia dónde se quiere ir, sin saber cómo, que saber cómo ir sin saber adónde!!!”. 


\section{Notas}

${ }^{1}$ Profesor Asociado IV, CPDA, Universidade Federal Rural do Rio de Janeiro. Investigador del CNPq, Brasil. Investigador visitante del Instituto Gino Germani, Universidad de Buenos Aires.

${ }^{1}$ Muchos proponen la subversión del vocabulario: “No me parece que valga la pena argumentar en los términos de la visión del mundo impuesta en todas partes. Debemos crear otro vocabulario, por completo. Hay ciertos términos que perdieron totalmente su sentido. Términos usados en la actualidad, como 'desarrollo`o 'democracia`y el modo en que se utilizan” (Berger, 2007). Para Boaventura de Souza Santos (2010), la hegemonía se connota en que los sustantivos de las agendas son puestos desde la derecha (“desarrollo”, “democracia”, etc.), y que la resistencia crítica sólo puede agregar adjetivos (“inclusivo”, "sostenible”, “participativa”, etc.).

3 “Apenas conocidos los aplastantes resultados electorales, Rafael Correa anunció que propondría un cambio en la Constitución (aquella célebre Constitución de los derechos de la naturaleza y del Buen Vivir) para permitir el ingreso de transgénicos que, en su opinión, son una clave para el aumento radical de la productividad agropecuaria. La investigación y el conocimiento, dijo, que pueden aplicarse a mejorar la calidad de vida de la gente, no pueden detenerse por novelerías” (Ospina, 2013). Pero ésta es otra historia, aunque también vinculada con el fetichismo del desarrollo de las fuerzas productivas.

${ }^{4}$ Habría inclusive una discusión más básica y pertinente: ¿puede considerarse a la extracción masiva de recursos minerales no renovables en bruto, en base a una tecnología importada y que son exportados sin elaboración como un "desarrollo de las fuerzas productivas”? En su lugar queda un agujero, y, además de cargar con un "pasivo ambiental” por los siglos venideros, el país cancela el recurso y, con él, cierra también las posibilidades de disponer de él, es decir, pierde alternativas de futuro. "En 2005 Brasil exportó U\$S 55,3 mil millones en materias primas y U\$S 44,2 mil millones en bienes manufacturados. En 2011 Brasil triplicó sus exportaciones de materias primas para U\$S 162,2 mil millones mientras sus exportaciones de manufacturas aumentaron para apenas U\$S 60,3 mil millones. En otras palabras, la diferencia entre el valor de las exportaciones de materias primas y de manufacturas aumentó de U\$S 13 mil millones para más de U\$S 100 mil millones en los últimos cinco años del régimen Lula. La desindustrialización relativa de la economía, el desequilibrio creciente entre el sector extractivo dominante y el sector manufacturero ilustra la reversión del Brasil para un estilo colonial de desarrollo” (Petras, 2013).

${ }^{5}$ Más de un siglo después de esta correspondencia entre Marx y Danielson, escribía Stephen Bunker (2011) en la introducción a un proyectado estudio sobre la mina de Carajás, en la Amazonia brasileña: "Os conflitos provocados pela mina demonstram que a pesada infra-estrutura de extração, transporte e sistemas de processamento em escala global alteram, de forma dramática, o ambiente físico, encolhendo ou eliminando economías locais anteriormente estabelecidas. Os riscos em jogo - o enorme capital irremediavelmente empregado em lugares remotos a fim de asegurar o acesso barato e estável às matérias-primas necessárias à produção competitiva e aos lucros no nível global, bem como os meios de subsistência e sobrevivência social no nível local - são extremamente elevados para todos os atores. Desigualdades maciças de 
poder, objetivos de ações e estilos organizacionais provocam uma violência destrutiva nos diferentes grupos que buscam obter e defender a matéria e o espaço que necessitam controlar a fim de reivindicar seus interesses (...) Carajás também mostra como novas economias de escala, impostas em zonas até então não incorporadas ao sistema mundial, desestabilizam sistemas ecológicos e sociais locais, aumentam a escala e a concentração de capital, diminuem a autoridade e autonomia dos estados locais, deixando à administração estatal com menos competência e menos recursos para controlar os numerosos problemas relacionados ao bem estar e à ordem social e à destruição ambiental trazida pelos projetos de escala global, com vastas demandas sobre a matéria localmente produzida. (...) As organizações políticas e econômicas locais não estão adaptadas para confrontar-se ou negociar com o poder infinitamente maior das associações estatais, empresariais e financeiras, nacionais e internacionais, necessárias para coordenar o licenciamento, financiamento, marketing, direitos de passagem e infra-estrutura de transporte inerentes a projetos tão intensivos em capital e extensivos em espaço"(págs. 128/130)

${ }^{6}$ La hambruna rusa de 1891 fue referida por Mike Davis (2002), junto con otras catástrofes provocadas por sequías en regiones periféricas (África, India, China, nordeste de Brasil). Según su interpretación, se trató en realidad de genocidios permitidos por los poderes coloniales, que destruyeron a las sociedades periféricas y permitieron el afianzamiento del imperialismo.

${ }^{7}$ Para referirnos a otro clásico, Claude Lévi-Strauss (1993) [1961] registró a la experiencia colonial como fundamento del capitalismo, estableciendo un modelo de reconfiguración social que luego sería aplicado sobre poblaciones y territorios subordinados en el interior de los países centrales. Ruy Mauro Marini (1972), por su parte, criticó a la perspectiva de André Gunder Frank por no diferenciar entre el colonialismo, basado en el saqueo sistemático de los recursos naturales americanos, y la dependencia, que implicaría una participación orgánica subordinada en la división internacional del trabajo, viable sólo a partir de 1840. En el mismo sentido se expresó Celso Furtado (1969), teniendo en cuenta las transformaciones en las tecnologías de navegación marítima (buques construidos de metal, propulsados a vapor), los ferrocarriles y la invención del telégrafo. Es una discusión aún abierta, o que puede serlo.

${ }^{8}$ Es conocida la relectura que David Harvey (2008) realizó de las posiciones de Rosa Luxemburgo para fundamentar su propuesta de la “acumulación por desposesión”.

${ }^{9}$ Claro que, en todo caso, habían sido “vaciados” de población indígena.

${ }^{10}$ Título del editorial, de autoría colectiva, de la revista Crisis, 5, Buenos Aires, junio/ julio 2011.

${ }^{11}$ Como ejemplo, escribía Celso Furtado en 1969: "De este modo, el avance de la industria minera de exportación se hizo con la desnacionalización de la misma y con la implantación de un sector productivo que, dado su gran avance tecnológico y elevada densidad de capital, tendió a aislarse, y a comportarse como un sistema económico separado, o mejor aún, como parte del sistema económico al que pertenecía la matriz de la unidad productora. El control extranjero de una actividad altamente capitalizada y que utiliza poca mano de obra significó desvincular del sistema económico interno la parte principal del flujo de ingreso originado en esa actividad. En tales condiciones, su valor como factor de transformación directa de las estructuras internas se redujo casi 
a nada. Además, como la infraestructura creada para servir a las industrias minerales de exportación es altamente especializada, las economías externas que resultan de la misma son escasas o nulas para el conjunto del sistema económico. Finalmente, al abastecerse de productos especializados obtenidos fuera del país y al producir un reducido flujo de salarios, este tipo de actividad no contribuyó de forma significativa en ninguna parte a la creación de un mercado interno”.

${ }^{12}$ Un análisis de Pablo Dávalos (2013), por ejemplo, muestra que en el caso de Ecuador la renta extractiva no financia políticas sociales, lo que inclusive es vedado por la Constitución. 
Polis, Revista Latinoamericana, Volumen 14, $N^{\circ}$ 41, 2015

\section{Bibliografía}

Alimonda, Héctor (2006), "Una nueva herencia en Comala (Apuntes sobre la ecología política latinoamericana y la tradición marxista)”, en Héctor Alimonda (compilador), Los tormentos de la materia - Aportes para una ecología política latinoamericana, CLACSO, Buenos Aires.

Alimonda, Héctor (2012), “Marxismo y ecología política latinoamericana Elementos para una genealogía posible”, en Nostromo - Revista Crítica Latinoamericana, México, otoño 2011/primavera 2012.

Aricó, José (1981) (compilador), Karl Marx - Nicolái Danielson - Friedrich Engels - Correspondencia 1868/1895, Biblioteca del Pensamiento Socialista, Siglo XXI, México.

Berger, John (2007), “La esperanza entre los dientes”, en Biodiversidad, sustento y culturas, 53, Montevideo, julio de 2007.

Bunker, Stephen (2011), “Matéria, espaço, tempo e globalização: o caso de Carajás na Amazônia brasileira”, en Héctor Alimonda (coordinador), La naturaleza colonizada - Ecologia política y mineria en América Latina, CLACSO/Ciccus, Buenos Aires.

Dávalos, Pablo (2013), “No podemos ser mendigos sentados en un saco de oro ` - Las falacias del discurso extractivista”, comunicación personal, 25 de mayo, 2013.

Davis, Mike (2002), Holocaustos coloniais - Clima, fome e imperialismo na formação do Terceiro Mundo, Record, Rio de Janeiro.

Gudynas, Eduardo (2013), “Hoy en América Latina, ¿Marx sería extractivista?, ALAI, Quito, 7 de febrero 2013.

Furtado, Celso (1969), La economía latinoamericana desde la conquista ibérica hasta la revolución cubana, Editorial Universitaria, Santiago de Chile.

Harvey, David (2008), “El neoliberalismo como destrucción creativa”, en Memoria, 232, México DF, agosto/septiembre 2008.

Lévi-Strauss, Claude (1993), “As descontinuidades culturais e o desenvolvimento econômico”, em Antropologia Estrutural II, Tempo Brasileiro, Rio de Janeiro.

Luxemburgo, Rosa (1967), La acumulación del capital, Grijalbo, México.

Marini, Ruy Mauro (1972), “Dialéctica de la dependencia: la economía exportadora”, en Sociedad y Desarrollo, 1, CESO - Universidad de Chile, Santiago, enero/marzo 1972. 
Martínez Alier, Joan (2013), “Marx y el extractivismo del presidente Correa”, en Alai, Quito, 25 de febrero 2013.

Ospina Peralta, Pablo (2013), Ecuador, el nuevo período de gobierno y el cambio de la matriz productiva, en CEP, Quito, julio 2013.

Petras, James, “Brasil, o capitalismo extractivo e o grande salto para trás”, resistir.info, 23/07/2013.

Santos, Boaventura de Souza (2010), Refundación del Estado en América Latina - Perspectivas desde una epistemología del Sur, Abya Yala/Universidad Politécnica Salesiana, Quito.

Recibido: 10.08.2015

Aceptado: 25.08.2015 